\title{
Acute and Subchronic Toxicity of Mulberry Fruits
}

\author{
${ }^{1,2}$ Jintanaporn Wattanathorn, ${ }^{1,2}$ Wipawee Thukummee, \\ ${ }^{1,2}$ Cholathip Thipkaew, ${ }^{1,2}$ Panakporn Wannanond, \\ ${ }^{1,2}$ Terdthai Tong-Un, ${ }^{1,2}$ Supaporn Muchimapura and ${ }^{3}$ Wiroje Kaewrueng \\ ${ }^{1}$ Integrative Complementary Alternative Medicine Research Group, Faculty of Medicine, \\ ${ }^{2}$ Department of Physiology, Faculty of Medicine, \\ Khon Kaen Unhiversity, Khon Kaen, 40002, Thailand \\ ${ }^{3}$ Department of Sericulture, Ministry of Agriculture and Cooperatives, Thailand
}

Received 2012-03-05, Revised 2012-05-13; Accepted 2012-05-14

\begin{abstract}
At present, the application of phytomedicine worldwide is substantial increase. The data of the acute and subchronic toxicity studies on medicinal plants or fruits and vegetables used for medicinal purposes should be obtained in order to increase the confidence in its safety to human, particularly for the application as functional food. Despite the widely consumption of mulberry (Morus alba L, Maraceae family) fruits both as fruit and as medicine, no systematic evaluation of the toxicity of mulberry fruits is available until now. This study aimed to determine the acute and subchronic oral toxicities of mulberry fruits in male and female Wistar rats. A single acute mulberry fruits extract dose of $2000 \mathrm{mg} \mathrm{kg}^{-1}$ dissolved in distilled water was administered by oral gavage for acute toxicity. Subchronic doses of 2, 10 and $500 \mathrm{mg} \mathrm{kg}^{-1}$ day ${ }^{-1}$ were also administered the same way for 90 days. The major toxicological endpoints examined included animal body weight, water and food intake, selected tissue weights and histopathological examinations. In addition, we also examined hematological and clinical chemistry values. The results showed no abnormalities in treated groups as compared to the controls. Although significantly different BUN and glucose were also observed, all of the values were within normal limits. Neither gross abnormalities nor histopathological changes were observed. The results suggest that mulberry fruits do not produce acute or subchronic toxicity in either female or male rats. Therefore mulberry fruits have the potential to be use as functional food. However, a chronic toxicity study should be further carried out to assure the safety for repetitive administration of this fruit before the application of functional food.
\end{abstract}

Keywords: Mulberry Fruits, Acute Toxicity, Subchronic Toxicity

\section{INTRODUCTION}

At present, there has been a substantial increase in the use of Complimentary Alternative Medicine. Due to the widespread use of Traditional and Complementary Alternative Medicine and the tremendous expansion of international markets for herbal products, it is all the more important to ensure that the health care provided by Traditional and Complementary Alternative Medicine is safe and reliable (Zhang, 2001). Among various types of Complimentary Alternative Medicine, phytomedicine is the most widely used.

Since ancient times, plants have been valued for their medicinal properties and many cultures still rely on plants as their major source of medicine. Numerous fruits and vegetables have been used as food and as one of the main source of drug discovery and development. However, only a few of them have been scientifically investigated, especially about their toxic aspects.

Mulberry (Morus alba L.) or Mohn in Thai, a plant in family of Moraceae, is widely cultivated in the North and North East of Thailand. Mulberry fruit is widely regarded as a nutritious food. It can be eaten freshly or widely used in the production of wine, fruit juice, jam and canned food (Ning et al., 2005). Mulberry fruit is not only used as fruit but also as medicine. According to the traditional folklore, mulberry fruit is used to protect against liver and kidney damage, strengthen the joints, improve eyesight and have anti-aging effects ( $\mathrm{Li}, 1982$ ). It is also used for the treatment of sore throat, fever, hypertension and anemia (Ma, 2002; Gong and Zhu, 
2008). In addition, recent findings showed that mulberry fruits could protect against brain damage in various conditions including Parkinson's disease (Kim et al., 2010) and cerebral ischemia (Kang et al., 2006). Moreover, mulberry fruit extract also decreased $\beta$-amyloid protein and improved learning impairment in SenescenceAccelerated Mice (SAMP) (Shih et al., 2010).

Although the safety of mulberry fruits can be assumed from their very long history of consumption in Asian countries, systematic evaluation of the toxicity of mulberry fruits has been lacking. Therefore, the purpose of this study was to investigate acute and subchronic oral toxicities of mulberry fruits.

\section{MATERIALS AND METHODS}

\subsection{Preparation of Mulberry Fruits Freeze- Dried Powder}

All mulberry fruits (Morus alba var Chiangmai) used in this study is prepared and provided by The Institute of Queen Sirikit Seri Culture, Thailand. Mulberry fruits were collected from the Queen Sirikit Seri Culture Center Udon Thani. All berries were picked at the commercially ripen stage and selected according to uniformity color. Then, the fruits were dried at $70^{\circ} \mathrm{C}$ for 4 days and grounded to powder. In addition, the mulberry fruit powders were also kept in dark air tight bottle at $20^{\circ} \mathrm{C}$. The mulberry fruit powder used in this study contained phenolic compounds at concentration of $519 \pm 0.004 \mathrm{mg} \mathrm{GAE} / \mathrm{g}$ fresh matter of fruit. It also contained anthocyanin at concentration of $667.95 \pm 0.07$ $\mathrm{mg}$ of Cyanidin-3-Glucoside Equivalents (CGE) per $100 \mathrm{~g}$ of fresh weight.

\subsection{Animal}

Adult male Wistar rats, 8 weeks old, were used as experiment animals. They were obtained from National Animal Center, Salaya, Nakornpatom. The weights of the animals on the first day of experiment were 180-220 grams. All animals were given access to food and water ad libitum. The experiments were performed to minimize animal suffering and the experimental protocols will be approved by the Institutional Animal Care and Use Committee Khon Kaen University, Thailand.

\subsection{Acute Toxicity Test}

Acute toxicity test was performed according to the World Health Organization (WHO) guideline (WHO, 1986) and the Organization of Economic Co-operation and Development (OECD) guideline for testing of chemicals (OECOD, 2001). Fiveteen rats per sex were administrated a single oral dose of $2,000 \mathrm{mg} \mathrm{kg}^{-1}$ body weight while the control group received water vehicle.
Body weight, signs of toxicity and mortality were observed after the administration at the first, second, fourth and sixth hour and once daily for next 14 days. On the 15 th day, all rats were kept fasted for $16-18 \mathrm{~h}$ and then sacrificed for necropsy examination. The internal organs were excised and weighed. The gross pathological observations of the tissues were performed.

\subsection{Subchronic Toxicity Test}

According to WHO guideline (WHO, 1986) and the OECD (OECOD, 1981), rats were divided into 5 groups of 30 animals (15 male and 15 female). According to the previous study, we have found that the effective doses 2-10 $\mathrm{mg} \mathrm{kg}{ }^{-1} \mathrm{BW}$ of powdered fruits significantly exerted the neuroprotection and cognitive enhancer effects. In the present study, the doses of mulberry cruits were 2, 10 and $500 \mathrm{mg} \mathrm{kg}^{-1}$ day $^{-1}$, which are cover the effective doses and the equivalent 50-250 times of effective dose (2-10 mg $\mathrm{kg}^{-1}$ ). The mulberry fruits powder were dissolved in distilled water and orally given to each group of rats daily for 90 days, while the control group received the water vehicle. Toxic manifestations such as signs of toxicity, mortality and the body weight changes were monitored daily. At the end of the study, all animals were fasted for 16-18 $\mathrm{h}$ and then anesthetized with intraperitoneal injection of pentobarbital sodium at a dose of $50 \mathrm{mg} \mathrm{kg}^{-1}$ on day $91 \mathrm{st}$. Blood samples for hematological and blood chemical analyses were taken from abdominal aorta. All rats were sacrificed after the blood collection. The internal organs and some tissues were weighed to determine relative organs weights and observed for gross lesions. All tissues were preserved in $10 \%$ neutral buffered formaldehyde solution for histopathological examination.

\subsection{Statistical Analysis}

Results were expressed as mean \pm Standard Error of Mean (SEM). Statistical significance was determined by one-way Analysis of Variance (ANOVA) and post hoc Least-Significant Difference (LSD) test. The data obtained from acute toxicity studies were analyzed using Student's paired t-test. P values less than 0.05 were considered significant.

\section{RESULTS}

\subsection{Acute Toxicity}

The powder of mulberry fruits at a single dose of 2000 $\mathrm{mg} \mathrm{kg}{ }^{-1}$ was orally given to rats. Neither sign of toxicity nor death of rats was observed during the 14 days of the experimental period. Toxicity evaluation was further carried out by observing both body weight gain and internal organ weight. Table 1 showed that no significant changes of the parameters mentioned earlier were observed. Furthermore, gross examinations of the internal 
organs of treated rats revealed no pathological abnormality as compared with those of the control (data not shown).

\subsection{Subchronic Toxicity}

Neither changes in animal behaviors nor toxic signs were detected in the treatment rats. The body weight and internal organ weight of both male and female rats after repetitive administration of mulberry fruits at doses of 2 , 10 and $500 \mathrm{mg} \mathrm{kg}^{-1}$ BW were shown in Table 2 and 3. Our data clearly demonstrated that no significant changes in the parameters just mentioned were observed.

All hematological values of male and female tested in this study were shown in Table 4 and 5. There were no treatment-related changes in all hematological parameters tested in this study. The blood chemistry values of male and female rats subjected to mulberry fruits treatment at all doses used in this study were demonstrated in Table 6 and 7. Table 6 showed that the Blood Urea Nitrogen
(BUN) of male rats significantly decreased $(\mathrm{p}<0.05$ compared to control). However, these values were still in the normal range (Johnson-Delaney and Harrison, 1996). No other changes were observed in this study. The BUN value of female rats subjected to mulberry fruits treatment at dose of $500 \mathrm{mg} \mathrm{kg}^{-1} \mathrm{BW}$ also showed the significant reduction of BUN as shown in Table 7. Again, this change was still in the normal range (Johnson-Delaney and Harrison, 1996). Moreover, all doses of mulberry fruits could produce significant elevation of glucose levels in female rats $(\mathrm{p}<0.05$ all; compared to control). The changes of blood sugar levels were also in the normal range (Johnson-Delaney and Harrison, 1996). No other significant clinical chemistry values were observed in both male and female rats. In addition, the results of the histopathological assessment showed no significant histopathological change in the internal, especially vital organs.

Table 1. The effect of mulberry fruits on body weight gain and internal organ weight.

\begin{tabular}{|c|c|c|c|c|}
\hline \multirow[b]{2}{*}{ Organs } & \multicolumn{4}{|c|}{ Dose of $M$. alba (g/kg BW/day) } \\
\hline & Male- Control & $\begin{array}{l}\text { Male } \\
2 \mathrm{~g} / \mathrm{kgBW}\end{array}$ & Female-Control & $\begin{array}{l}\text { Female } \\
2 \mathrm{~g} / \mathrm{kgBW}\end{array}$ \\
\hline Final body weight & $281.80 \pm 4.09$ & $282.33 \pm 9.54$ & $255 \pm 3.72$ & $243 \pm 3.63$ \\
\hline Brain & $7.10 \pm 0.12$ & $6.76 \pm 0.24$ & $7.85 \pm 0.18$ & $7.73 \pm 0.16$ \\
\hline Lung & $8.20 \pm 0.35$ & $10.30 \pm 0.72$ & $7.76 \pm 0.32$ & $7.82 \pm 0.51$ \\
\hline Heart & $4.25 \pm 0.18$ & $4.45 \pm 0.18$ & $3.42 \pm 0.08$ & $3.46 \pm 0.08$ \\
\hline Liver & $34.67 \pm 1.55$ & $38.62 \pm 1.51$ & $33.17 \pm 0.74$ & $35.92 \pm 1.34$ \\
\hline Right Kidney & $4.03 \pm 0.12$ & $4.08 \pm 0.14$ & $3.45 \pm 0.13$ & $3.33 \pm 0.08$ \\
\hline Left Kidney & $4.16 \pm 0.15$ & $4.22 \pm 0.15$ & $3.31 \pm 0.07$ & $3.46 \pm 0.08$ \\
\hline Spleen & $3.80 \pm 0.27$ & $4.05 \pm 0.18$ & $2.74 \pm 0.17$ & $2.92 \pm 0.09$ \\
\hline Pancreas & $6.82 \pm 0.38$ & $6.27 \pm 0.55$ & $5.83 \pm 0.23$ & $5.77 \pm 0.37$ \\
\hline GI Tract & $79.07 \pm 1.91$ & $84.83 \pm 3.33$ & $96.41 \pm 1.32$ & $94.94 \pm 4.24$ \\
\hline Right Testis/Ovary & $7.11 \pm 0.16$ & $7.08 \pm 0.25$ & $2.03 \pm 0.16$ & $2.15 \pm 0.12$ \\
\hline Left Testis/Ovary & $7.33 \pm 0.24$ & $7.08 \pm 0.3$ & $2.28 \pm 0.25$ & $2.21 \pm 0.18$ \\
\hline Adrenal gl. & $0.38 \pm 0.04$ & $0.40 \pm 0.05$ & $0.40 \pm 0.06$ & $0.46 \pm 0.04$ \\
\hline Right Salivary gland & $0.61 \pm 0.04$ & $0.64 \pm 0.02$ & $0.52 \pm 0.04$ & $0.55 \pm 0.04$ \\
\hline Left Salivary gland & $0.71 \pm 0.06$ & $0.66 \pm 0.05$ & $0.54 \pm 0.04$ & $0.53 \pm 0.03$ \\
\hline Thymus & $1.77 \pm 0.05$ & $1.50 \pm 0.16$ & $1.52 \pm 0.13$ & $1.48 \pm 0.09$ \\
\hline
\end{tabular}

* significantly different from control group $(\mathrm{p}<0.05>$ The values are expressed as mean \pm S.E.M.)

Table 2. Body weight $(\mathrm{g})$ and relative organ weight $(\mathrm{g} / \mathrm{kg})$ of male rats receiving $M$. alba for 3 months

\begin{tabular}{|c|c|c|c|c|}
\hline \multirow[b]{2}{*}{ Organs } & \multirow[b]{2}{*}{ Control } & \multicolumn{3}{|c|}{ Dose of $M$. alba $(\mathrm{mg} / \mathrm{kg} \mathrm{BW} /$ day $)$} \\
\hline & & 21 & 0 & 500 \\
\hline Initial body weight & $206.00 \pm 4$ & $234.000 \pm 12$ & $220.000 \pm 2$ & $234.000 \pm 13$ \\
\hline Final body weight & $398.10 \pm 8$ & $378.000 \pm 8$ & $435.000 \pm 6^{*}$ & $420.000 \pm 7^{*}$ \\
\hline Brain & $5.02 \pm 0.06$ & $5.110 \pm 0.13$ & $4.810 \pm 0.10$ & $4.850 \pm 0.11$ \\
\hline Lung & $5.80 \pm 0.23$ & $6.690 \pm 0.66$ & $6.570 \pm 0.37$ & $6.490 \pm 0.67$ \\
\hline Heart & $3.02 \pm 0.16$ & $3.280 \pm 0.08$ & $3.050 \pm 0.05$ & $3.050 \pm 0.06$ \\
\hline Liver & $24.51 \pm 1.00$ & $26.860 \pm 0.62$ & $24.720 \pm 0.41$ & $25.310 \pm 0.65$ \\
\hline Right Kidney & $2.85 \pm 0.09$ & $3.030 \pm 0.10$ & $2.910 \pm 0.07$ & $2.920 \pm 0.09$ \\
\hline Left Kidney & $2.95 \pm 0.12$ & $3.130 \pm 0.10$ & $2.780 \pm 0.10$ & $3.000 \pm 0.09$ \\
\hline Spleen & $2.69 \pm 0.43$ & $3.000 \pm 0.12$ & $2.280 \pm 0.14$ & $2.460 \pm 0.09$ \\
\hline Pancreas & $4.83 \pm 0.28$ & $4.640 \pm 0.41$ & $4.310 \pm 0.35$ & $4.660 \pm 0.35$ \\
\hline GI Tract & $55.90 \pm 1.02$ & $56.670 \pm 2.03$ & $53.980 \pm 1.24$ & $56.250 \pm 1.18$ \\
\hline Right Testis & $5.03 \pm 0.1$ & $5.250 \pm 0.17$ & $5.020 \pm 0.11$ & $4.850 \pm 0.15$ \\
\hline Left Testis & $5.19 \pm 0.15$ & $5.240 \pm 0.19$ & $5.010 \pm 0.07$ & $4.540 \pm 0.27$ \\
\hline Adrenal gl. & $0.27 \pm 0.03$ & $0.300 \pm 0.03$ & $0.341 \pm 0.026$ & $0.290 \pm 0.02$ \\
\hline Right Salivary gland & $0.44 \pm 0.05$ & $0.482 \pm 0.018$ & $0.421 \pm 0.027$ & $0.420 \pm 0.024$ \\
\hline Left Salivary gland & $0.51 \pm 0.05$ & $0.485 \pm 0.035$ & $0.451 \pm 0.036$ & $0.502 \pm 0.049$ \\
\hline Thymus & $1.25 \pm 0.04$ & $1.240 \pm 0.11$ & $1.230 \pm 0.03$ & $1.260 \pm 0.07$ \\
\hline
\end{tabular}

* significantly different from control group $(\mathrm{p}<0.05>$ The values are expressed as mean \pm S.E.M. 
Table 3. Body weight $(\mathrm{g})$ and relative organ weight $(\mathrm{g} / \mathrm{kg})$ of female rats receiving $M$. albafor 3 months

\begin{tabular}{|c|c|c|c|c|}
\hline \multirow[b]{2}{*}{ Organs } & \multicolumn{4}{|c|}{ Dose of M. alba (mg/kg BW/day) } \\
\hline & Control & 2 & 10 & 500 \\
\hline Initial body weight & $219.000 \pm 3$ & $231.000 \pm 3 *$ & $219.000 \pm 2$ & $224.000 \pm 6$ \\
\hline Final body weight & $255.000 \pm 4$ & $251.000 \pm 3$ & $250.000 \pm 2$ & $255.000 \pm 2$ \\
\hline Brain & $7.860 \pm 0.18$ & $7.460 \pm 0.13$ & $7.750 \pm 0.09$ & $7.870 \pm 0.15$ \\
\hline Lung & $7.770 \pm 0.32$ & $8.400 \pm 0.52$ & $7.610 \pm 0.51$ & $8.030 \pm 0.55$ \\
\hline Heart & $3.420 \pm 0.09$ & $3.340 \pm 0.07$ & $3.350 \pm 0.07$ & $3.450 \pm 0.07$ \\
\hline Liver & $33.180 \pm 0.75$ & $34.980 \pm 0.93$ & $34.740 \pm 1.07$ & $32.870 \pm 1.12$ \\
\hline Right Kidney & $3.460 \pm 0.13$ & $3.230 \pm 0.08$ & $3.520 \pm 0.11$ & $3.370 \pm 0.12$ \\
\hline Left Kidney & $3.320 \pm 0.08$ & $3.340 \pm 0.07$ & $3.640 \pm 0.18$ & $3.250 \pm 0.09$ \\
\hline Spleen & $2.740 \pm 0.17$ & $2.820 \pm 0.09$ & $2.900 \pm 0.16$ & $2.740 \pm 0.12$ \\
\hline Pancreas & $5.840 \pm 0.22$ & $5.590 \pm 0.37$ & $6.170 \pm 0.37$ & $6.070 \pm 0.45$ \\
\hline GI Tract & $96.420 \pm 1.32$ & $96.080 \pm 3.25$ & $94.760 \pm 4.57$ & $90.140 \pm 3.71$ \\
\hline Right Ovary & $2.040 \pm 0.17$ & $2.080 \pm 0.12$ & $2.070 \pm 0.13$ & $1.830 \pm 0.20$ \\
\hline Left Ovary & $2.290 \pm 0.25$ & $2.130 \pm 0.18$ & $2.420 \pm 0.29$ & $1.810 \pm 0.18$ \\
\hline Adrenal gl. & $0.406 \pm 0.061$ & $0.448 \pm 0.041$ & $0.409 \pm 0.041$ & $0.432 \pm 0.036$ \\
\hline Right Salivary gland & $0.522 \pm 0.042$ & $0.538 \pm 0.043$ & $0.564 \pm 0.038$ & $0.521 \pm 0.029$ \\
\hline Left Salivary gland & $0.541 \pm 0.045$ & $0.512 \pm 0.037$ & $0.529 \pm 0.034$ & $0.580 \pm 0.063$ \\
\hline Thymus & $1.520 \pm 0.13$ & $1.430 \pm 0.09$ & $1.49 \pm 0.07$ & $1.540 \pm 0.11$ \\
\hline
\end{tabular}

* significantly different from control group $(\mathrm{p}<0.05>$ The values are expressed as mean \pm S.E.M.)

Table 4. The effect of mulberry fruits on all hematological values of male for 3 months

\begin{tabular}{|c|c|c|c|c|}
\hline \multirow[b]{2}{*}{ Parameters } & \multicolumn{4}{|c|}{ Dose of $M$. alba $(\mathrm{mg} / \mathrm{kg} \mathrm{BW} /$ day $)$} \\
\hline & Control & 2 & 10 & 500 \\
\hline Hematocrit (\%) & $48.30 \pm 1.61$ & $47.11 \pm 1.55$ & $44.040 \pm 4.48$ & $46.210 \pm 0.64$ \\
\hline $\mathrm{RBC}\left(\times 106\right.$ cells $\left./ \mathrm{mm}^{3}\right)$ & $7.91 \pm 0.30$ & $7.53 \pm 0.53$ & $7.680 \pm 0.74$ & $8.150 \pm 0.10$ \\
\hline Hemoglobin $(\mathrm{g} / \mathrm{dl})$ & $16.53 \pm 0.23$ & $14.89 \pm 0.70$ & $15.160 \pm 1.47$ & $16.050 \pm 0.18$ \\
\hline $\mathrm{MCV}(\mu \mathrm{m} 3 /$ red cell $)$ & $61.39 \pm 1.97$ & $58.43 \pm 0.73$ & $52.280 \pm 5.17$ & $56.700 \pm 0.43$ \\
\hline MCH (pg/red cell) & $21.15 \pm 0.78$ & $18.53 \pm 0.71$ & $18.110 \pm 1.77$ & $19.720 \pm 0.17$ \\
\hline $\mathrm{MCHC}(\mathrm{g} / \mathrm{dl}$ RBC $)$ & $34.54 \pm 1.18$ & $31.74 \pm 1.22$ & $31.560 \pm 3.13$ & $34.770 \pm 0.22$ \\
\hline WBC $\left(\times 103\right.$ cells $\left./ \mathrm{mm}^{3}\right)$ & $4.39 \pm 0.39$ & $3.90 \pm 0.25$ & $3.880 \pm 0.55$ & $3.650 \pm 0.35$ \\
\hline Neutrophil (\%) & $14.88 \pm 2.01$ & $19.94 \pm 1.47$ & $16.780 \pm 2.16$ & $19.037 \pm 0.78$ \\
\hline Lymphocyte (\%) & $73.39 \pm 3.87$ & $66.32 \pm 1.79$ & $61.840 \pm 6.26$ & $67.970 \pm 1.68$ \\
\hline Monocyte (\%) & $8.20 \pm 1.81$ & $8.55 \pm 0.87$ & $8.024 \pm 1.01$ & $8.180 \pm 0.94$ \\
\hline Eosinophil (\%) & $3.19 \pm 0.76$ & $3.74 \pm 0.61$ & $3.791 \pm 0.56$ & $4.160 \pm 0.58$ \\
\hline Basophil (\%) & $0.34 \pm 0.02$ & $0.33 \pm 0.04$ & $0.360 \pm 0.07$ & $0.320 \pm 0.02$ \\
\hline Platelet $\left(\times 103\right.$ cells $\left./ \mathrm{mm}^{3}\right)$ & $593.30 \pm 74.36$ & $587.86 \pm 43.29$ & $593.480 \pm 82.23$ & $575.920 \pm 47.40$ \\
\hline
\end{tabular}

* significantly different from control group $(\mathrm{p}<0.05>$ The values are expressed as mean \pm S.E.M.)

Table 5. The effect of mulberry fruits on all hematological values of female for 3 months

\begin{tabular}{|c|c|c|c|c|}
\hline \multirow[b]{2}{*}{$\underline{\text { Parameters }}$} & \multicolumn{4}{|c|}{ Dose of M. alba (mg/kg BW/day) } \\
\hline & Control & 2 & 10 & 500 \\
\hline Hematocrit (\%) & $48.25 \pm 0.82$ & $49.25 \pm 0.80$ & $44.98 \pm 1.20$ & $49.77 \pm 1.54$ \\
\hline $\mathrm{RBC}\left(\times 106\right.$ cells $\left./ \mathrm{mm}^{3}\right)$ & $8.23 \pm 0.15$ & $8.32 \pm 0.12$ & $7.64 \pm 0.21$ & $8.14 \pm 0.16$ \\
\hline Hemoglobin $(\mathrm{g} / \mathrm{dl})$ & $16.15 \pm 0.21$ & $16.21 \pm 0.22$ & $15.14 \pm 0.33$ & $16.05 \pm 0.34$ \\
\hline $\operatorname{MCV}(\mu \mathrm{m} 3 /$ red cell $)$ & $58.65 \pm 0.73$ & $59.17 \pm 0.72$ & $58.9 \pm 0.470$ & $61.13 \pm 1.23$ \\
\hline $\mathrm{MCH}(\mathrm{pg} /$ red cell $)$ & $19.65 \pm 0.23$ & $19.48 \pm 0.18$ & $19.87 \pm 0.25$ & $19.72 \pm 0.21$ \\
\hline MCHC (g/dl RBC) & $33.51 \pm 0.42$ & $32.96 \pm 0.35$ & $33.74 \pm 0.35$ & $32.37 \pm 0.38$ \\
\hline WBC $\left(\times 103\right.$ cells $\left./ \mathrm{mm}^{3}\right)$ & $4.35 \pm 0.10$ & $4.36 \pm 0.16$ & $3.73 \pm 0.37$ & $3.35 \pm 0.37$ \\
\hline Neutrophil (\%) & $19.94 \pm 1.17$ & $21.62 \pm 1.30$ & $20.22 \pm 0.59$ & $20.47 \pm 1.93$ \\
\hline Lymphocyte (\%) & $71.84 \pm 1.71$ & $71.88 \pm 1.61$ & $70.81 \pm 1.10$ & $66.60 \pm 4.09$ \\
\hline Monocyte (\%) & $5.38 \pm 1.09$ & $3.74 \pm 0.26$ & $5.24 \pm 0.60$ & $5.27 \pm 0.55$ \\
\hline Eosinophil (\%) & $1.93 \pm 0.40$ & $2.20 \pm 0.45$ & $2.86 \pm 0.54$ & $2.81 \pm 0.37$ \\
\hline Basophil (\%) & $0.33 \pm 0.04$ & $0.55 \pm 0.10$ & $0.40 \pm 0.04$ & $0.55 \pm 0.09$ \\
\hline Platelet $\left(\times 103\right.$ cells $\left./ \mathrm{mm}^{3}\right)$ & $685.5 \pm 32.04$ & $675.26 \pm 50.42$ & $695.33 \pm 51.31$ & $682.07 \pm 51.72$ \\
\hline
\end{tabular}

* significantly different from control group $(\mathrm{p}<0.05>$ The values are expressed as mean \pm S.E.M.) 
Table 6. Biological values of male rats receiving $M$. alba for 3 months

\begin{tabular}{|c|c|c|c|c|}
\hline \multirow[b]{2}{*}{ Parameters } & \multicolumn{4}{|c|}{ Dose of $M$. alba $(\mathrm{mg} / \mathrm{kg} \mathrm{BW} /$ day $)$} \\
\hline & Control & 2 & 10 & 500 \\
\hline AST (U/L) & $186.80 \pm 9.60$ & $192.60 \pm 8.46$ & $221.27 \pm 9.77$ & $226.67 \pm 13.35$ \\
\hline Bilirubin $(\mathrm{mg} / \mathrm{dl})$ & $2.54 \pm 0.21$ & $1.99 \pm 0.16$ & $2.59 \pm 0.11$ & $3.36 \pm 0.21 *$ \\
\hline BUN $(\mathrm{mg} / \mathrm{ml})$ & $25.20 \pm 3.09$ & $16.93 \pm 0.50 *$ & $18.80 \pm 0.55^{*}$ & $17.47 \pm 1.05 *$ \\
\hline Glucose $(\mathrm{mg} / \mathrm{dl})$ & $81.40 \pm 4.76$ & $82.87 \pm 2.08$ & $73.60 \pm 1.52$ & $98.67 \pm 2.89 *$ \\
\hline Uric acid (mg/dl) & $10.84 \pm 1.58$ & $6.95 \pm 0.31 *$ & $8.35 \pm 0.36^{*}$ & $9.33 \pm 0.60$ \\
\hline Triglyceride $(\mathrm{mg} / \mathrm{dl})$ & $110.00 \pm 4.95$ & $103.27 \pm 4.05$ & $116.93 \pm 5.58$ & $116.73 \pm 7.36$ \\
\hline Cholesterol (mg/dl) & $151.40 \pm 1.11$ & $152.20 \pm 1.03$ & $150.73 \pm 0.52$ & $151.47 \pm 0.79$ \\
\hline
\end{tabular}

* significantly different from control group $(\mathrm{p}<0.05>$ The values are expressed as mean \pm S.E.M.)

Table 7. Biological values of female rats receiving M. alba for 3 months

\begin{tabular}{|c|c|c|c|c|}
\hline \multirow[b]{2}{*}{ Parameters } & \multicolumn{4}{|c|}{ Dose of $M$. alba $(\mathrm{mg} / \mathrm{kg} \mathrm{BW} /$ day $)$} \\
\hline & Control & 2 & 10 & 500 \\
\hline$\overline{\mathrm{AST}}(\mathrm{U} / \mathrm{L})$ & $261.00 \pm 17.26$ & $266.33 \pm 16.02$ & $258.87 \pm 8.85$ & $266.47 \pm 22.32$ \\
\hline Bilirubin (mg/dl) & $3.06 \pm 0.21$ & $3.31 \pm 0.25$ & $3.29 \pm 0.19$ & $3.29 \pm 0.16$ \\
\hline BUN (mg/ml) & $26.80 \pm 1.32$ & $26.60 \pm 0.87$ & $26.20 \pm 0.81$ & $22.80 \pm 0.93 *$ \\
\hline Glucose $(\mathrm{mg} / \mathrm{dl})$ & $85.60 \pm 1.77$ & $100.00 \pm 2.07 *$ & $97.13 \pm 1.85 *$ & $89.53 \pm 3.33$ \\
\hline Uric acid (mg/dl) & $7.64 \pm 0.48$ & $8.17 \pm 0.43$ & $7.59 \pm 0.45$ & $8.16 \pm 0.56$ \\
\hline Triglyceride (mg/dl) & $123.00 \pm 11.42$ & $113.00 \pm 6.80$ & $129.33 \pm 9.14$ & $126.70 \pm 9.26$ \\
\hline Cholesterol $(\mathrm{mg} / \mathrm{dl})$ & $151.00 \pm 0.80$ & $150.40 \pm 0.21$ & $150.67 \pm 0.41$ & $151.53 \pm 0.96$ \\
\hline
\end{tabular}

* significantly different from control group $(\mathrm{p}<0.05>$ The values are expressed as mean \pm S.E.M.)

\section{DISCUSSION}

In acute toxicity study, mulberry fruits at a single dose of $2,000 \mathrm{mg} \mathrm{kg}^{-1}$ did not show any toxicity signs (body weight, internal organ weight and general behaviors). The results suggest that mulberry fruits are practically not toxic after an acute exposure in rats.

Commonly, mulberry fruits could provide beneficial effects after the repetitive consumption over a long period. Unfortunately, little toxicity information is available regarding safety following repeated exposure. The effects of mulberry fruits exposure in subchronic regimen appeared to vary by sex. Generally, no changes in body weight, organ weights, hematological values and histopathological data were observed while a slight but significant reduction of BUN in both male and female were observed. The previous data which reported the effect of BryophyllumPinnatum (Lam.) on the hematological values showed non defference in Sprague-Dawley Rats (Raymond et al., 2010). The reduction of this parameter might be due to the increase water concentration much more than the pathophysiology of liver because no data in this study indicated the liver damage. In addition, our data also demonstrated that the female rats showed trends to increase blood sugar level following mulberry administration much more than male. Based on the previous data which reported the difference in carbohydrate and fat metabolism between male and female (Gustavsson et al., 2010) and high carbohydrate especially fructose content in mulberry fruits, we did suggest that the increase blood sugar level in female rat might be associated with the lower carbohydrate metabolism in female rat. However, all changes observed in this study were still in normal range. Therefore, our data suggested that the No Adverse Effect Level (NOAEL) dose in both male and female were $500 \mathrm{mg} \mathrm{kg}^{-1} \mathrm{BW}$.

\section{CONCLUSION}

Mulberry fruits administered orally did not cause acute and subchronic toxicities in male or female rats. However, a chronic toxicity study should be further carried out to assure the safety for repetitive administration of this fruit before the application of functional food.

\section{ACKNOWLEDGEMENT}

This study was supported by The Queen Sirikit Department of Sericulture, Ministry of Agriculture and Cooperatives, Thailand and Integrative Complementary and Alternative Medicine Research and Development Group, Khon Kaen University, Thailand.

\section{REFERENCES}

Gong, S.X. and J.P. Zhu, 2008. Mulberry relieving nutritional anemi. J. Zhejiang Univ. Trad. Chin. Med., 32: 350-352. 
Gustavsson, C., K. Yassin, E. Wahlstrom, L. Cheung and J. Lindberg et al., 2010. Sex-different hepaticglycogen content and glucose output in rats. BMC Biochem., 11: 38-38. PMID: 20863371

Johnson-Delaney, C.A. and L.R. Harrison, 1996. Exotic Companion Medicine Handbook for Veterinarians. 1st Edn., Wingers Pub., Lake Worth, ISBN-10: 0963699644, pp: 400.

Kang, T.H., J.Y. Hur, H.B. Kim, J.H. Ryu and S.Y. Kim, 2006. Neuroprotective effects of the cyanidin-3-Obeta-d-glucopyranoside isolated from mulberry fruit against cerebral ischemia. Neurosci. Lett., 391: 122126. PMID: 16181734

Kim, H.G., M.S. Ju, J.S. Shim, M.C. Kim and S.H. Lee et al., 2010. Mulberry fruit protects dopaminergic neurons in toxin-induced Parkinson's disease models. Br. J. Nutr., 104: 8-16. PMID: 20187987

Li, S.Z., 1982. Compendium of Materia Medica. 1st Edn., People's Medical Press, Beijing.

Ma, Y.P., 2002. Clinical observation of mulberry as a medicine of pharyngitis treatment. Xinjiang J. Trad. Chin. Med., 20: 83-84.

Ning, D.W., B. Lu and Y.L. Zhang, 2005. The processing technology of mulberry series product. China Fruit Veg. Proc., 5: 38-40.

OECOD, 1981. Agricultural Advisory Services in OECD Member Countries. 1st Edn., Organisation for Economic Co-Operation and DeveSlopment, Paris, ISBN-10: 9264121269, pp: 241.
OECOD, 2001. OECD guideline for Testing of Chemicals. 1st Edn., OECD Library, ISBN: 9789264070820, pp: 11.

Raymond, I.O., E.I. Sylvester and E.T. Glory, 2010. Acute and sub-acute toxicological assessment of aqueous leaf extract of BryophyllumPinnatum (Lam.) in sprague-dawley rats. Am. J. Pharmacol. Toxicol., 5: 145-151. DOI: 10.3844/ajptsp.2010.145.151

Shih, P.H., Y.C. Chan, J.W. Liao, M.F. Wang and G.C. Yen, 2010. Antioxidant and cognitive promotion effects of anthocyanin-rich mulberry (Morus atropurpurea L.) on senescence-accelerated mice and prevention of Alzheimer's disease. J. Nutr. Biochem., 21: 598-605. PMID: 19443193

WHO, 1986. Principles of Toxicokinetic Studies. 1st Edn., Stationery Office Books, ISBN-10: 9241542578, pp: 166.

Zhang, X., 2001. Legal Status of Traditional Medicine and Complementary/Alternative Medicine: A Worldwide Review. 1st Edn., World Health Organization, Geneva, ISBN-10: 9241545488, pp: 189. 